\title{
Effect of acute ingestion of fresh and stored lettuce (Lactuca sativa) on plasma total antioxidant capacity and antioxidant levels in human subjects
}

\author{
Mauro Serafini*, Rossana Bugianesi, Monica Salucci, Elena Azzini, Anna Raguzzini and \\ Giuseppe Maiani \\ Antioxidant Research Laboratory at the Unit of Human Nutrition, Istituto Nazionale di Ricerca \\ per gli Alimenti e la Nutrizione (INRAN), Rome, Italy
}

(Received 16 November 2001 - Revised 6 June 2002 - Accepted 18 July 2002)

\begin{abstract}
The present study investigated whether storage under modified-atmosphere packaging (MAP) affected the antioxidant properties of fresh lettuce (Lactuca sativa). Eleven healthy volunteers (six men, five women) consumed $250 \mathrm{~g}$ fresh lettuce, and blood was sampled before $(0 \mathrm{~h})$ and 2 , 3 and $6 \mathrm{~h}$ after consumption. The protocol was repeated $3 \mathrm{~d}$ later with the same lettuce stored at $5^{\circ} \mathrm{C}$ under MAP conditions $\left(\mathrm{O}_{2}-\mathrm{N}_{2}(5: 95, \mathrm{v} / \mathrm{v})\right)$. Results showed that after ingestion of fresh lettuce, plasma total radical-trapping antioxidant potential (TRAP), measured as area under the curve, was significantly higher $(1.3($ SEM 0.3$) \mathrm{mmol} / \mathrm{l}$ per $6 \mathrm{~h} ; P<0.05)$ than the value obtained with MAP-stored lettuce $(0 \cdot 1$ (SEM $0 \cdot 2) \mathrm{mmol} / \mathrm{l}$ per $6 \mathrm{~h}$ ). Plasma TRAP, quercetin and $p$-coumaric acid were significantly different from baseline values $(P \leq 0.05) 2$ and $3 \mathrm{~h}$ after fresh lettuce ingestion. Caffeic acid increased significantly at $3 \mathrm{~h}(P<0 \cdot 05)$. Plasma $\beta$-carotene levels increased significantly at $6 \mathrm{~h}(P<0 \cdot 05)$. Vitamin $\mathrm{C}$ concentrations $(\mathrm{mg} / \mathrm{l})$ rose from 10.9 (SEM 2.0) to 12.7 (SEM 3.0) $(P<0.001), 12.7$ (SEM 2.0) $(P<0.01)$ and 12.9 (SEM 3.0) $(P<0.05)$ at $0,2,3$ and $6 \mathrm{~h}$ respectively. No changes were observed after ingestion of MAPstored lettuce for all the measured markers. Our present results showed that ingestion of MAP-stored lettuce does not modify plasma redox status in healthy subjects. Further research is needed to develop post-harvesting techniques able to preserve the bioactive molecule content of plant food.
\end{abstract}

Plasma antioxidant capacity: Modified-atmosphere packaging: Vegetables: Bioavailability

The existing scientific evidence regarding a primary role for fruits and vegetables in preventing degenerative diseases is consistent and trustworthy (Gey et al. 1987; Block et al. 1992). However, the exact mechanism for the link between plant food consumption and the decreased mortality rates for these diseases has not yet been fully elucidated. The precise nature of the compounds that may be involved in this protective function and the mechanisms responsible for it are still unclear. However, in recent years, several antioxidant nutrients present in plant food, such as vitamin $\mathrm{C}$ and vitamin $\mathrm{E}$, have been suggested to exert a protective role against the diseases mentioned earlier (Halliwell, 1996). The mechanism by which they are supposed to act in man is based on their direct or indirect modulation of in vivo oxidative stress. Recent increasing evidence supports the hypothesis that other hitherto scarcely studied molecules, such as phenolic compounds, could also play an essential health-promoting role (Duthie et al. 2000).

Over the last few decades, nutrition policies have strongly promoted the consumption of a diet containing $>400 \mathrm{~g}$ fresh vegetables and fruits/d as a nutritional goal for health promotion. On the one hand, consumer response to healthy eating campaigns has created a sustained and increasing demand for foods that are 'healthier', free from contaminants, pesticides or additives. On the other hand, sociological factors, such as the lack of time necessary for purchasing fresh products from the market place, cooking them in a domestic setting and serving them according to traditional methods, hinder the conversion to a healthier, more natural way of living. These conditions have stimulated an increasing demand for 'ready-to-eat' vegetables, leading to a flourishing market of pre-packed fresh products, 
packaged under different conditions to extend shelf-life. The most studied and widely used packaging method for storing raw fruits and vegetables is modified-atmosphere packaging (MAP) (Kader et al. 1989; Powrie \& Skura, 1991). The aim of MAP is to create an optimal gas balance inside the package, where the respiration activity of a product is as low as possible and the concentrations of $\mathrm{O}_{2}$ and $\mathrm{CO}_{2}$ are not detrimental to the product. In the past few years, 'ready-to-use' MAP-stored lettuce, one of the most widely consumed dietary vegetables, has become very popular and fresh-cut lettuce stored in polypropylene film is available in many supermarkets. However, due to the high respiration rates and the browning processes during storage, the antioxidant molecules present in vegetables could become oxidised (Brecht, 1980). Therefore, it appears important to assess if vegetables retain their antioxidant activity in vivo and whether bioavailability of their bioactive compounds is somehow modified by MAP storage conditions. In the present study, we assessed whether post-harvest MAP storage affected the in vitro and in vivo antioxidant properties of lettuce (Lactuca sativa). In addition, we determined whether the plasma redox status of human subjects responds to the acute ingestion of fresh lettuce, identifying the bioactive antioxidant molecules involved.

\section{Materials and methods}

\section{Subjects and protocol}

Eleven healthy volunteers (six men and five women) aged 29-45 years were recruited from the Istituto Nazionale di Ricerca per gli Alimenti e la Nutrizione (INRAN; Rome, Italy) staff. Subjects were non-smokers, normolipidaemic and taking no drug or vitamin supplements, with a mean weight of 63.8 (SEM 10.5) (range 48.0-86.0) $\mathrm{kg}$ and BMI 22.2 (SEM 2.2) (range 19.4-27.5) $\mathrm{kg} / \mathrm{m}^{2}$. Each subject signed a consent form approved by the Human Subjects Committee of INRAN. On two different days, subjects consumed fresh lettuce (phase 1) and stored lettuce (phase 2). The first day of the present study (phase 1), a butterfly needle was inserted into a forearm vein of the subjects after they had fasted for $12 \mathrm{~h}$ and baseline blood samples were collected. After blood collection, subjects consumed $250 \mathrm{~g}$ fresh lettuce and venous blood samples were collected at 2, 3 and $6 \mathrm{~h}$ into vacutainer tubes containing heparin or $\mathrm{Na}^{+}$EDTA as anticoagulant. Blood samples were immediately centrifuged at $3000 \mathrm{~g}$ for $10 \mathrm{~min}\left(4^{\circ} \mathrm{C}\right)$, plasma was separated and placed at $-80^{\circ} \mathrm{C}$ for analyses. Total radical-trapping antioxidant potential (TRAP) was measured within $3 \mathrm{~h}$ of the blood collection. A portion of plasma was immediately stabilised with metaphosphoric acid ( $0.75 \mathrm{~mol} / \mathrm{l}$; BDH Laboratory Supplies, Poole, Dorset, $\mathrm{UK}$ ) and stored at $-80^{\circ} \mathrm{C}$ for vitamin $\mathrm{C}$ analysis. The protocol was repeated after $3 \mathrm{~d}$ (phase 2); this time, each subject $(n 8)$ received $250 \mathrm{~g}$ of the same lettuce used in phase 1 stored at $+5^{\circ} \mathrm{C}$ under MAP conditions.

\section{Preparation of plant material}

Lettuce (Lactuca sativa, $7 \mathrm{~kg}$ ), obtained from a local agricultural cooperative, was harvested on the same day, the outer wrapped leaves of lettuce were discarded, the edible part was washed and chopped into small pieces and divided into two portions: one was given to the subjects (phase 1) and the other was stored under MAP conditions at $+5^{\circ} \mathrm{C}$ until administration (phase 2). The lettuce $(250 \mathrm{~g})$ was put into $30 \mu \mathrm{m}$ polypropylene film bags and subjected to the MAP treatment. MAP packaging was achieved by flushing $\mathrm{O}_{2}-\mathrm{N}_{2}(5: 95, \mathrm{v} / \mathrm{v})$ for $10 \mathrm{~s}$ into the bags before heat sealing. The gas content in each bag of lettuce was analysed with a Servomax $1100 \mathrm{~A} \mathrm{O}_{2}$ analyser (Taylor Instruments Analytic Ltd, Crowborough, Sussex, UK) and Morgan $8010 \mathrm{CO}_{2}$ analyser (PK Morgan, Chatham, Kent, UK). Lettuce samples were also used for food composition analysis and for assessing the effect of time on the in vitro antioxidant capacity of fresh and MAP-stored lettuce.

\section{Chemicals}

All solvents and reagents were HPLC or Optima grade; common reagents were purchased from Sigma (St Louis, MO, USA), Carlo Erba (Milan, Italy) and BDH Laboratory Supplies, and were the highest grade available.

\section{Phenolic hydrolysis and extraction from food and plasma}

Food polyphenols were hydrolysed to obtain aglyconic forms and extracted as previously described (Hertog et al. 1992) with some modifications. Briefly, one whole plant of lettuce was stripped of the outer wrapped leaves and divided longitudinally in two equal parts. Each part was washed, dried and chopped into small pieces by hand. One part was homogenised and analysed, while the other was subjected to MAP treatment as described earlier (p. 616) and homogenised just before analysis. Polyphenols were extracted from $3 \mathrm{~g}$ homogenised lettuce with ethyl acetate after acidic hydrolysis with $\mathrm{HCl}-$ methanol (1:1, $\mathrm{v} / \mathrm{v})$ at $90^{\circ} \mathrm{C}$ for $2 \mathrm{~h}$ exactly as described by Hertog et al. (1992).

Plasma circulating phenols (caffeic acid, p-coumaric acid and quercetin) were detected in their free form after enzymatic and acidic hydrolysis of the conjugated forms. To perform the enzymatic hydrolysis, $0.5 \mathrm{ml}$ enzymatic solution containing $5.5 \times 10^{5} \mathrm{U}$ sulfatase and $1.0 \times 10^{7} \mathrm{U}$ $\beta$-glucoronidase (sulfatase S 3009 type H-5 from Helix pomatia, also containing $\beta$-glucoronidase; Sigma)/litre $0.2 \mathrm{M}$-acetate buffer ( $\mathrm{pH} \mathrm{5)}$ were added to $0.5 \mathrm{ml}$ plasma. The mixture was then incubated at $37^{\circ} \mathrm{C}$ for $45 \mathrm{~min}$. Immediately afterwards, acidic hydrolysis was performed by incubating the mixture with $1 \mathrm{ml} 3 \mathrm{M}-\mathrm{HCl}-\mathrm{MeOH}$ $(1: 1, \mathrm{v} / \mathrm{v})$ for $30 \mathrm{~min}$ at room temperature. Phenols were extracted by adding $2 \mathrm{ml}$ ethyl acetate, followed by $3 \mathrm{~min}$ stirring and sonication for $1 \mathrm{~min}$ before centrifugation at $1700 \mathrm{~g}$ for $5 \mathrm{~min}$. The extraction procedure was repeated twice and the two organic layers were combined and evaporated under an $\mathrm{N}_{2}$ flow. The residue was dissolved into $250 \mu$ l mobile phase (phosphate buffer ( $\mathrm{pH} 2 \cdot 8$ )-methanol $(1: 1, \mathrm{v} / \mathrm{v}))$.

\section{Chromatography}

Quantitative analysis of caffeic acid, $p$-coumaric acid and quercetin was performed by a HPLC system comprising 
an ESA MODEL 540 refrigerated autoinjector $\left(4^{\circ} \mathrm{C}\right)$, an ESA MODEL 580 solvent delivery module with two pumps, an ESA 5600 eight-channel coulometric electrode array detector and the ESA coularray operating software, which controlled all the equipment and carried out the data processing (ESA, Chelmsford, MA, USA). Phenols in the extracts were separated by a Supelcosil LC-18 (particle size $5 \mu \mathrm{m})$ column $(25.0 \times 4.6 \mathrm{~cm})$ with a Perisorb Supelguard LC-18 (Supelco, Bellefonte, PA, USA) at the temperature of $30^{\circ} \mathrm{C}$ maintained by a column heater. Injection was performed with an autoinjector (100 $\mu$ l fixed loop) and the volume injected was $30 \mu \mathrm{l}$. The mobile phase comprised two solvents: a sodium phosphate monobasic solution $(0.01 \mathrm{M}$ brought to $\mathrm{pH} 2.8$ with orthophosphoric acid $(850 \mathrm{ml} / \mathrm{l})$ (buffer, solvent A)) and methanol (solvent B). Solvent A was filtered through a $0.2 \mu \mathrm{m}$ membrane filter. The linear gradient applied consisted of $87 \%$ solvent A, decreasing linearly to $60 \%$ over $13.5 \mathrm{~min}$, to $10 \%$ after a further $26.5 \mathrm{~min}$, reaching the final conditions of $0 \%$ $3.0 \mathrm{~min}$ later. The elution program returned to $87 \%$ of solvent A over $3 \mathrm{~min}$, maintaining these conditions for $4 \mathrm{~min}$ before the subsequent injection. The flow rate of the eluent was constant at $1 \mathrm{ml} / \mathrm{min}$ and the setting potentials were: 60, 120, 200, 340, 580, 620, 760 and $900 \mathrm{mV}$ (v. Palladium reference electrode). The phenols peaks were determined by matching sample peaks with standard peaks on the basis of their retention time $( \pm 4 \%)$ and on the accuracy ratio between adjacent channels $( \pm 30 \%)$ (Svendsen, 1993).

The method of the external standard was used for the calibration. Standard stock solution containing caffeic acid, $p$-coumaric acid and quercetin in methanol was stored at $-20^{\circ} \mathrm{C}$. The stability of the standard was checked every day by u.v. spectroscopy for all the period of the present study. The calibration graphs for each polyphenol were obtained by a least squares linear fitting of the peak height $(\mathrm{nA})$ of the dominant channel $v$. phenol concentration $(\mathrm{mg} / \mathrm{l})$. Standard curves were constructed every day of the present study to check the daily instrumentation performance.

\section{Method validation}

Since the method used for polyphenols determination in food was validated by the authors (Hertog et al. 1992) only for flavonoid class and using lyophilised plant material, we performed a validation study to verify the method suitability. Precision was estimated as the CV of intra- and inter-day replicate analyses. For both hydroxycinnamic acids and quercetin, a $\mathrm{CV}<8(n$ 10) and $<10 \%$ ( $n$ 20) was found for intra- and inter-day precision respectively.

Due to the lack of blank matrix, the method of standard addition was used in order to evaluate intra- and inter-day method bias by comparing the slopes of the standard addition line with the calibration line. Standard addition was performed by preparing four different solutions of $p$-coumaric acid, of caffeic acid and of quercetin: $0 \cdot 25$, $0.5,1.0$ and $2.0 \mathrm{~g} / 1$ methanol. Each solution $(200 \mu \mathrm{l})$ was used to spike a sample of homogenised lettuce $(3 \mathrm{~g})$ that was processed exactly as described earlier. The procedure was repeated in triplicate on two different occasions. An intra-day bias $<7 \%$ and inter-day bias $<12 \%$ was found for each compound tested.

The same experiment conducted to calculate bias was used to deduce recovery data. Relative recovery was calculated by dividing the difference between the responses of spiked and non-spiked processed samples by the response of pure unprocessed standard. A recovery $>90 \%$ was calculated at each concentration for both hydroxycinnamic acids and quercetin.

To evaluate accuracy, precision and absolute recovery of the method used to analyse polyphenols in plasma, we analysed spiked samples in a concentration range bracketing the interval in which experimental values fall, in replicates of four, on two separate occasions. Spiked samples were prepared at four concentrations of each standard (quercetin, caffeic and $p$-coumaric acid) ranging between 12 and $100 \mu \mathrm{g} / \mathrm{l}$, adding a suitable volume of a solution containing $0.5 \mathrm{mg}$ standard $/ 1$ methanol and $500 \mu \mathrm{l}$ previously analysed plasma to ascertain the absence of quercetin, caffeic and $p$-coumaric acid over limit of detection (calculated as the amount of polyphenol resulting in a peak height of three times the standard deviation of the baseline noise). Spiked samples were processed and analysed exactly as described earlier. For all polyphenols tested, a $\mathrm{CV}<5 \%$ was found for intra-day precision, while a $\mathrm{CV}<8 \%$ was calculated for inter-day precision. Bias $<10 \%$ and recovery $>8 \%$ was found for each compound.

\section{Measurement of the total antioxidant capacity of plasma and lettuce: total radical-trapping antioxidant potential assay}

The method (Ghiselli et al. 1995) is based on the protection afforded by plasma or other substrate, against the decay of a fluorescent target, $R$-phycoerythrin during a controlled peroxidation reaction. In the present study, plasma or lettuce extract was added to the reaction mixture, made up to a final volume of $2.0 \mathrm{ml}$ and pre-incubated at $37^{\circ} \mathrm{C}$ for $5 \mathrm{~min}$ in $10 \mathrm{~mm}$ quartz fluorometer cells. The oxidation reaction was started by adding a peroxyl radical generator (2,2'-azobis(2-amidinopropane) dihydrochloride) to a final concentration of $5.0 \mathrm{~mm}$. The results were standardised using 6-hydroxy-2,5,7,8-tetramethyl-chroman-2-carboxylic acid, a water-soluble analogue of $\alpha$-tocopherol, and expressed as $\mu \mathrm{mol}$ peroxyl radicals trapped per litre plasma or per $g$ lettuce.

The edible portion of lettuce was homogenised in a blender after the addition of deionised water $(1: 2, \mathrm{w} / \mathrm{v})$ (Cao et al. 1996). The homogenate was then centrifuged at $34000 \mathrm{~g}$ for $30 \mathrm{~min}\left(4^{\circ} \mathrm{C}\right)$. The supernatant fraction (water-soluble) was recovered and used directly for the TRAP assay. The residue was washed twice with deionised water and further extracted using pure acetone $(1: 4, \mathrm{w} / \mathrm{v})$, and shaking at room temperature for $30 \mathrm{~min}$. The acetone extract (liposoluble fraction) was recovered after centrifugation $\left(34000 \mathrm{~g}, 10 \mathrm{~min}, 4^{\circ} \mathrm{C}\right)$, and the supernatant fraction was used for the TRAP assay. The TRAP value of the lettuce was obtained by adding 
together the TRAP value of the water- and liposoluble fractions.

\section{Other measurements}

The total polyphenol content in lettuce was quantified following a colorimetric assay with Folin-Ciocalteau reagent (Swain \& Hillis, 1959). Vitamin C was extracted according to Margolis et al. (1990) and Margolis \& Schapira (1997) respectively for food and plasma. Plasma and food vitamin C was measured according to Margolis \& Schapira (1997) with slight modifications. Vitamin C signals were detected using the coulometric electrode array detector previously described for phenolic determination. The setting potential was $0,100,200,300$ and $400 \mathrm{mV}$ ( $v$. Palladium reference electrode). The flow rate was $0.8 \mathrm{ml} / \mathrm{min}$ and the volume injected was $30 \mu \mathrm{l}$. Carotenoids ( $\alpha$-carotene, $\beta$-carotene and lycopene) were determined exactly as described by Maiani et al. (1995) for plasma and by Sharpless et al. (1999) for food. Carotenoid separation was performed by injecting $50 \mu \mathrm{l}$ reconstituted extract on a Waters Nova Pack $\mathrm{C}_{18}$ column (particle size $4 \mu \mathrm{m} ; 39 \times 150 \mathrm{~mm}$ ) (Waters Millipore Corporation, Milford, MA, USA) and eluting isocratically mobile phase (methanol-acetonitrile-tetrahydrofuran (50:45:5, by vol.) at $1 \mathrm{ml} / \mathrm{min}$. Carotenoid extracts were analysed by an HPLC system, Perkin-Elmer ISS 200 with four pumps (Perkin-Elmer, Norwalk, CT, USA), coupled with a programmable sample injector. Carotenoid peaks were detected at $450 \mathrm{~nm}$ with a variable spectrophotometric detector (Perkin-Elmer LC-95; Perkin-Elmer) connected to a personal computer Pe-Nelson mod 1020 (PerkinElmer).

\section{Statistics}

All variables were tested for normality with the Kolmogorov-Smirnoff test. For normal variables (quercetin, $p$-coumaric acid, $\alpha$-carotene, vitamin $\mathrm{C}$ and lycopene), a repeated-measures ANOVA was used to assess changes over time and paired $t$ tests to test each pairwise comparison. When the variable distribution differed significantly from normal (TRAP, caffeic acid and $\beta$-carotene), the Friedman test was used to assess changes over time and the Wilcoxon test for post-hoc comparisons. All data were entered in an Excel database and analysed with STATISTICA for Windows (release 4.5, 1993; StatSoft Inc., Vigonza, PD, Italy). Values are reported as mean values with their standard errors, unless otherwise noted. Statistical significance was set at the 0.05 level. All $P$ values are two-tailed.

\section{Results}

\section{Modified-atmosphere packaging storage and lettuce antioxidant properties in vitro}

The changes in the concentration of vitamin $\mathrm{C}, p$-coumaric acid, caffeic acid, quercetin, $\beta$-carotene and TRAP in lettuce initially and after 3 and $7 \mathrm{~d}$ storage in air or under MAP conditions at $+5^{\circ} \mathrm{C}$ are described in Table 1. The TRAP value of air- and MAP-stored lettuce rapidly decreased (36 and $33 \%$ respectively) during the first $3 \mathrm{~d}$ of storage, followed by a very slow decay after $7 \mathrm{~d}$ (42 and $45 \%$ respectively). The decrease of the concentrations of phenolics paralleled the TRAP time course, i.e. a quick decay during the first $3 \mathrm{~d}$ and a less pronounced loss during the next $4 \mathrm{~d}$. $\beta$-Carotene and vitamin $C$ content decreased dramatically during both air and MAP storage, reaching less than one-half of the initial values after $3 \mathrm{~d}$ and almost disappearing after $7 \mathrm{~d}$ (Table 1).

\section{Analysis of lettuce antioxidant profile and total antioxidant potential}

The bioactive molecule content of fresh lettuce administered to the subjects, (total phenolics, $p$-coumaric acid, caffeic acid, quercetin, vitamin $\mathrm{C}$ and $\beta$-carotene) and in vitro TRAP value are reported in Table 2 . Results are given as total content in the dose $(250 \mathrm{~g})$ administered to the subjects.

Table 1. Changes in the concentration of vitamin $C, p$-coumaric acid, caffeic acid, quercetin, $\beta$-carotene and total radical-trapping antioxidant potential (TRAP) in lettuce after 3 and $7 \mathrm{~d}$ of storage in air or under modified-atmosphere packaging (MAP) at $5^{\circ} \mathrm{C} \dagger$

(Mean values and standard deviations for two experiments in triplicate)

\begin{tabular}{|c|c|c|c|c|c|c|c|c|c|c|c|c|}
\hline & \multicolumn{2}{|c|}{ TRAP $\ddagger$} & \multicolumn{2}{|c|}{$\begin{array}{l}\text { Coumaric } \\
\text { acid } \neq\end{array}$} & \multicolumn{2}{|c|}{ Caffeic acid $\ddagger$} & \multicolumn{2}{|c|}{ Quercetin $\ddagger$} & \multicolumn{2}{|c|}{$\beta$-Carotene } & \multicolumn{2}{|c|}{ Vitamin C $\ddagger$} \\
\hline & Mean & SD & Mean & SD & Mean & SD & Mean & SD & Mean & SD & Mean & SD \\
\hline $\begin{array}{l}\text { Baseline } \\
\text { Air }\end{array}$ & 100 & 26 & 100 & 5 & 100 & 5 & 100 & 14 & 100 & 27 & 100 & 30 \\
\hline Day 3 & $67^{*}$ & 11 & $79^{*}$ & 5 & $77^{*}$ & 1 & $43^{\star}$ & 16 & $37^{*}$ & 8 & $39^{*}$ & 4 \\
\hline $\begin{array}{l}\text { Day } 7 \\
\text { MAP }\end{array}$ & $55^{*}$ & 4 & $60^{*}$ & 14 & $60^{*}$ & 3 & $28^{*}$ & 10 & $23^{*}$ & 7 & $14^{*}$ & 4 \\
\hline Day 3 & $64^{*}$ & 3 & $56^{*}$ & 11 & $67^{*}$ & 3 & $36^{\star}$ & 12 & $42^{*}$ & 16 & $37^{*}$ & 5 \\
\hline Day 7 & $58^{*}$ & 5 & $47^{\star}$ & 8 & $63^{*}$ & 1 & $31^{*}$ & 11 & $17^{*}$ & 7 & $24^{*}$ & 5 \\
\hline
\end{tabular}

Mean values were significantly different from baseline value: ${ }^{*} P \leq 0.05$.

†For details of procedures, see p. 616 .

‡Results are expressed as \% baseline value. 
Table 2. Total radical-trapping antioxidant potential (TRAP), phenolic compounds, ascorbic acid and carotenoid concentrations in $250 \mathrm{~g}$ fresh lettuce (as is basis)

(Mean values with their standard errors for three experiments in triplicate)

\begin{tabular}{|c|c|c|}
\hline \multirow[b]{2}{*}{ Compound } & \multicolumn{2}{|c|}{ Concentration } \\
\hline & Mean & SE \\
\hline Total phenolics (mg QE) & 433.8 & $31 \cdot 0$ \\
\hline Coumaric acid (mg) & $7 \cdot 3$ & 0.5 \\
\hline Caffeic acid (mg) & 31.7 & $5 \cdot 7$ \\
\hline Quercetin (mg) & $12 \cdot 7$ & 1.8 \\
\hline Vitamin C (mg) & $26 \cdot 7$ & $2 \cdot 0$ \\
\hline$\beta$-Carotene (mg) & $1279 \cdot 4$ & $66 \cdot 3$ \\
\hline TRAP $(\mu \mathrm{mol}) \dagger$ & 992.5 & $25 \cdot 1$ \\
\hline
\end{tabular}

\section{$\mathrm{QE}$, quercetin equivalents.}

${ }^{*}$ For details of procedures, see p. 616

tTRAP values are expressed as $\mu \mathrm{mol}$ peroxyl radicals trapped by $250 \mathrm{~g}$ lettuce and represent the sum of the hydrosoluble and liposoluble fractions.

\section{Plasma total antioxidant potential}

In order to assess if post-harvest MAP storage affected the in vivo antioxidant properties of lettuce, we measured the area under the curve of the individual response of plasma TRAP values over the entire observation period. The mean value of area under the curve for the MAP-stored lettuce $(0.1$ (SEM 0.2$) \mathrm{mmol} / \mathrm{l}$ per $6 \mathrm{~h})$ was significantly lower (two-tailed paired $t$ test, $P<0.05$ ) than the value obtained for fresh lettuce (13.0 (SEM 27.0) $\mathrm{mmol} / \mathrm{l}$ per $6 \mathrm{~h}$ ). In order to give an idea of the order of magnitude of the increase of TRAP after fresh lettuce ingestion, \% increase over baseline values (not significantly different between phase 1 and phase 2) are shown in Fig. 1. Fresh lettuce consumption significantly increased plasma TRAP values (Friedman test, $P<0 \cdot 01)$. TRAP values $(\mathrm{mmol} / \mathrm{l})$ increased from a baseline level of 0.8 (SEM $0 \cdot 1)$ to 1.0

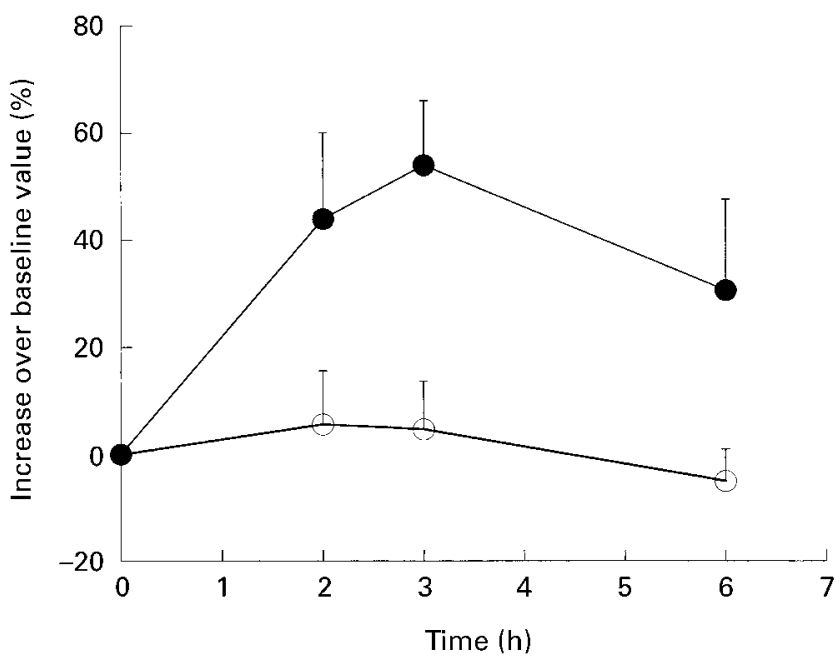

Fig. 1. Effect of acute ingestion of fresh $(\bullet ; n$ 11) and modifiedatmosphere packaging-stored $(0 ; n$ 8) lettuce on plasma total antioxidant capacity. Values are means of the individual \% increments over baseline values with standard errors shown by vertical bars. For details of subjects and procedures, see p. 616 .
(SEM 0.2 ) at $2 \mathrm{~h}$ (Wilcoxon test, $P<0 \cdot 05$ ), peaking at $3 \mathrm{~h}$ (1.1 (SEM 0.2); Wilcoxon test, $P<0.001$ ) and beginning to decrease after $6 \mathrm{~h}(0.9$ (SEM 0.09)) (Fig. 1). MAPstored lettuce did not induce any changes in plasma TRAP during the period of observation $(\mathrm{mmol} / \mathrm{l}): 0.9$ (SEM 0.06), 1.0 (SEM 0.07), 1.0 (SEM 0.9), 0.9 (SEM 0.5) at $0,1,2$ and $6 \mathrm{~h}$ respectively (Fig. 1).

\section{Levels of plasma phenolic compounds, carotenoids and vitamin $C$}

In the attempt to identify the molecules responsible for the in vivo redox activity of fresh lettuce, we measured plasma concentrations of the main antioxidants present in lettuce. For this purpose, we developed a selective and sensitive

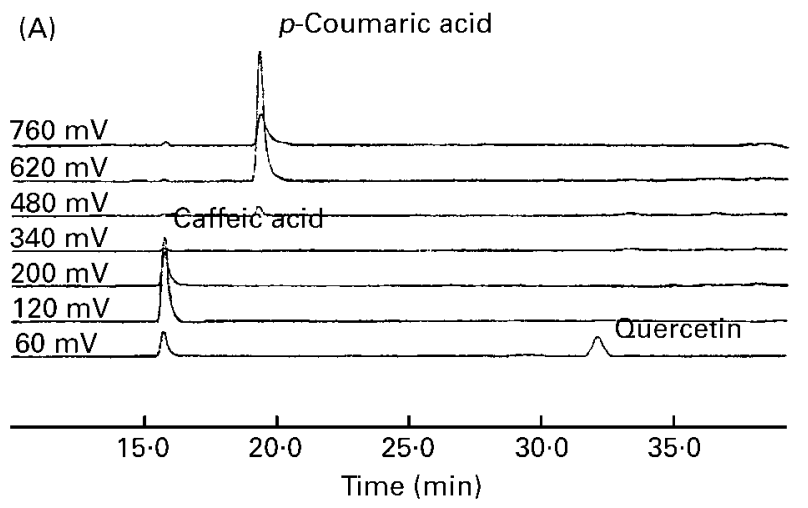

(B)

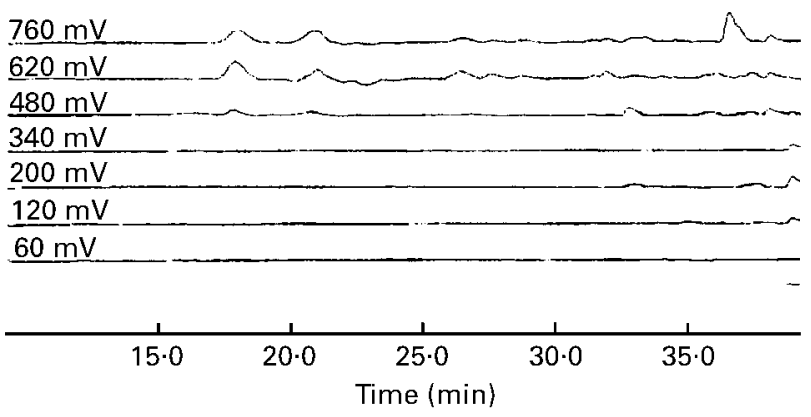

(C)

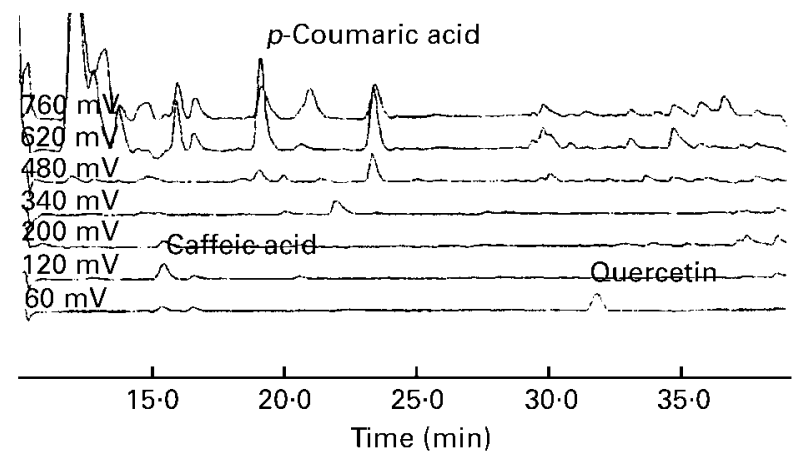

Fig. 2. Representative chromatograms of: (A) standards (caffeic acid, $p$-coumaric acid and quercetin) mixture; (B) plasma samples before consumption of fresh lettuce; (C) plasma samples $3 \mathrm{~h}$ after consumption of fresh lettuce, from one of the volunteers. For details of extraction procedures and chromatographic conditions, see p. 617. All the unnamed peaks are to be considered unknown. 
method to measure specific phenolic acids (caffeic and $p$-coumaric acid) and the flavonoid quercetin in plasma, using HPLC with electrochemical detection. Typical HPLC chromatograms of standards (caffeic acid, $p$-coumaric acid and quercetin) mixture and of a plasma extract before and after fresh lettuce ingestion are shown in Fig. 2. The chromatogram shown in Fig. 2(C) shows a clear increase of caffeic acid at $15.58 \mathrm{~min}$, in $p$-coumaric acid at $19.21 \mathrm{~min}$ and in quercetin at $31.88 \mathrm{~min}$ compared with the chromatogram obtained before fresh lettuce consumption (Fig. 2(B)). Mean plasma concentrations of caffeic acid, $p$-coumaric acid and quercetin after ingestion of fresh and MAP-stored lettuce are described in Table 3. Fresh lettuce consumption significantly increased caffeic acid (Friedman test, $P<0 \cdot 01$ ), $p$-coumaric acid (ANOVA, $P<0.001$ ) and quercetin (ANOVA, $P<0.01$ ) concentrations. The concentration of phenolics at $2 \mathrm{~h}$ was significantly greater than baseline values for both $p$-coumaric acid and quercetin (Table 3). Quercetin, caffeic acid and $p$-coumaric acid concentrations reached a peak at $3 \mathrm{~h}$, mirroring the time trend described for plasma antioxidant capacity. Ingestion of MAP-stored lettuce failed to modify plasma phenolic concentrations (Table 3), confirming the results obtained for TRAP values. Fresh lettuce ingestion significantly raised vitamin $\mathrm{C}$ concentration (ANOVA, $P<0.001$ ); the increase was observed $2 \mathrm{~h}$ $(P<0.001), 3 \mathrm{~h}(P<0.01)$ and $6 \mathrm{~h}(P<0.05)$ after the ingestion of fresh lettuce (Table 4$)$, paralleling TRAP results. In contrast, plasma concentrations of carotenoids were not modified by the ingestion of fresh lettuce, except for $\beta$-carotene (Friedman test, $P<0 \cdot 01$ ) (Table 4). Ingestion of MAP-stored lettuce did not change either plasma concentrations of carotenoids or vitamin C (Table 4).

\section{Discussion}

The effect of post-harvesting storage conditions on the loss of micronutrients is usually assessed utilising in vitro models (Gil et al. 1999). In the present study, we followed a different and innovative approach, determining the biological effect of the stored food in vivo on the total antioxidant capacity of plasma. This biomarker has been shown to be strongly related to the dietary intake of fruits and vegetables: an association between dietary antioxidant capacity, intake of plant food and in vivo plasma antioxidant potential has been described (Cao et al. 1998). Furthermore, in a randomised clinical trial on 123 healthy individuals, a plant food-rich diet (with high antioxidant potential) was shown to reduce the free radical load in vivo and to increase plasma TRAP more than a diet low in plant food (four servings per d) (Miller et al. 1998). The importance of this information is underlined by previous studies showing that total antioxidant capacity of plasma is significantly lower (with regard to controls) in subjects affected by HIV infection (McLemore et al. 1998), diabetes (Ceriello et al. 1998), systemic inflammatory disorders (Tsai et al. 2000) and lung cancer (Erhola et al. 1997).

Our present results clearly show that ingestion of fresh lettuce increases the antioxidant capacity of plasma in healthy subjects, whereas the same lettuce, stored for $3 \mathrm{~d}$ under MAP conditions, fails to modify plasma antioxidant defences. Moreover, we showed that $3 \mathrm{~d}$ of MAP storage significantly affected the content of bioactive molecules in lettuce, leading to an overall decrease in its in vitro antioxidant capacity. Our present results are in agreement with Gil et al. (1999), who showed a marked decrease of the in vitro total antioxidant activity and ascorbic acid content in spinach stored under MAP conditions.

MAP technology has been shown to prevent ripening and browning, slowing respiration, retaining moisture and extending the shelf-life of the stored items (Kader et al. 1989). However, on the basis of our present results, MAP storage does not preserve the bioactive antioxidant compounds present in the lettuce. Under MAP conditions, plant food inside the package is exposed to a low $\mathrm{O}_{2}$ atmosphere $(5 \%)$ with a consequent decrease in $\mathrm{O}_{2}$ availability for the plant cells. The biochemistry of cells and

Table 3. Plasma concentrations of caffeic acid, p-coumaric acid and quercetin before and after ingestion of $250 \mathrm{~g}$ fresh or modified-atmosphere packaging (MAP)-stored lettuce $\dagger$ (Mean values with their standard errors for eleven subjects for fresh lettuce and eight subjects for MAP lettuce)

\begin{tabular}{|c|c|c|c|c|c|c|c|c|}
\hline & \multicolumn{8}{|c|}{ Time (h) } \\
\hline & \multicolumn{2}{|c|}{0} & \multicolumn{2}{|c|}{2} & \multicolumn{2}{|c|}{3} & \multicolumn{2}{|c|}{6} \\
\hline & Mean & SE & Mean & SE & Mean & SE & Mean & SE \\
\hline \multicolumn{9}{|c|}{ Caffeic acid $(\mu \mathrm{g} / \mathrm{l})$} \\
\hline Fresh & 34.0 & $14 \cdot 0$ & $52 \cdot 0$ & $16 \cdot 0$ & $63 \cdot 0^{*}$ & $18 \cdot 0$ & $44 \cdot 0$ & $16 \cdot 0$ \\
\hline MAP & $22 \cdot 0$ & $4 \cdot 0$ & $24 \cdot 0$ & $5 \cdot 0$ & $22 \cdot 0$ & $4 \cdot 0$ & $16 \cdot 0$ & $4 \cdot 0$ \\
\hline \multicolumn{9}{|c|}{$p$-Coumaric aicd $(\mu \mathrm{g} / \mathrm{l})$} \\
\hline Fresh & $46 \cdot 0$ & $13 \cdot 0$ & $78 \cdot 0^{\star \star}$ & $11 \cdot 0$ & $85 \cdot 0^{* *}$ & $11 \cdot 0$ & $46 \cdot 0$ & $12 \cdot 0$ \\
\hline MAP & $42 \cdot 0$ & $17 \cdot 0$ & $32 \cdot 0$ & $13 \cdot 0$ & $35 \cdot 0$ & $14 \cdot 0$ & $32 \cdot 0$ & $14 \cdot 0$ \\
\hline \multicolumn{9}{|c|}{ Quercetin $(\mu \mathrm{g} / \mathrm{l})$} \\
\hline Fresh & $46 \cdot 0$ & $7 \cdot 0$ & $59 \cdot 0^{\star \star}$ & $6 \cdot 0$ & $66 \cdot 0^{* \star}$ & $6 \cdot 0$ & $54 \cdot 0$ & $6 \cdot 0$ \\
\hline MAP & $23 \cdot 0$ & $7 \cdot 0$ & $25 \cdot 0$ & $7 \cdot 0$ & 24.0 & $6 \cdot 0$ & $26 \cdot 0$ & 8.0 \\
\hline
\end{tabular}

Mean values were significanlty different from values at $0 \mathrm{~h}$ (two-tailed paired $t$ test for $p$-coumaric acid and quercetin and Wilcoxon test for caffeic acid): ${ }^{*} P<0.05$, ${ }^{\star *} P<0.01$.

$\dagger$ For details of subjects and procedures, see p. 616 . 
Table 4. Plasma concentrations of vitamin $\mathrm{C}$ and carotenoids before and after ingestion of $250 \mathrm{~g}$ fresh or modified-atmosphere packaging (MAP)-stored lettuce $\dagger$

(Mean values with their standard errors for eleven subjects for fresh lettuce and eight subjects for MAP lettuce)

\begin{tabular}{|c|c|c|c|c|c|c|c|c|}
\hline & \multicolumn{8}{|c|}{ Time (h) } \\
\hline & \multicolumn{2}{|c|}{0} & \multicolumn{2}{|c|}{2} & \multicolumn{2}{|c|}{3} & \multicolumn{2}{|c|}{6} \\
\hline & Mean & SE & Mean & SE & Mean & SE & Mean & $\mathrm{SE}$ \\
\hline \multicolumn{9}{|c|}{ Vitamin C (mg/l) } \\
\hline Fresh & 10.9 & $2 \cdot 0$ & $12 \cdot 7^{\star \star \star}$ & $3 \cdot 0$ & $12 \cdot 7^{\star \star}$ & $2 \cdot 0$ & $12 \cdot 9^{*}$ & 3.0 \\
\hline MAP & 11.5 & $2 \cdot 7$ & 11.0 & $2 \cdot 2$ & $10 \cdot 4$ & $3 \cdot 2$ & $12 \cdot 0$ & 3.4 \\
\hline \multicolumn{9}{|c|}{$\alpha$-Carotene $(\mu \mathrm{g} / \mathrm{l})$} \\
\hline Fresh & 44.0 & $10 \cdot 0$ & 44.0 & $10 \cdot 0$ & $45 \cdot 0$ & $10 \cdot 0$ & 53.0 & 11.0 \\
\hline MAP & 38.0 & 11.0 & $32 \cdot 1$ & $10 \cdot 0$ & 38.0 & 11.0 & $32 \cdot 0$ & 11.0 \\
\hline \multicolumn{9}{|c|}{$\beta$-Carotene $(\mu \mathrm{g} / \mathrm{l})$} \\
\hline Fresh & 333 & 74 & 310 & 70 & 346 & 73 & $402^{\star}$ & 86 \\
\hline MAP & 360 & 69 & 321 & 65 & 377 & 67 & 331 & 74 \\
\hline \multicolumn{9}{|c|}{ Lycopene $(\mu \mathrm{g} / \mathrm{l})$} \\
\hline Fresh & 333 & 40 & 304 & 29 & 350 & 32 & 291 & 30 \\
\hline MAP & 204 & 30 & 212 & 35 & 224 & 37 & 200 & 21 \\
\hline
\end{tabular}

Mean values were significantly different from values at $\mathrm{Oh}$ (two-tailed paired $t$ test for vitamin $\mathrm{C}$ and Wilcoxon test for $\beta$-carotene): ${ }^{\star} P<0.05,{ }^{* *} P<0.01,{ }^{* * \star} P<0.001$.

$\dagger$ For details of subjects and procedures, see p. 616.

cellular functions changes dramatically under hypoxic conditions and, paradoxically, cells become more susceptible to oxidative injury at low $P_{\mathrm{O}_{2}}$. One of the factors contributing to hypoxic injury is 'reductive stress', in which the concentration of potential electron donors is increased (lack of $\mathrm{O}_{2}$ to act as an electron acceptor results in increased reduction of all electron carriers in the chain). The accumulation of reducing equivalents can result in enhanced formation of reactive oxygen species either by direct electron donation to $\mathrm{O}_{2}$ or by redox cycling (a process whereby a low-molecular-mass 'mediator' accepts one electron from a reduced cellular component and transfers that electron to produce $\mathrm{O}_{2}^{-}$) (Jones, 1985).

The 'reductive/oxidative stress' originating from hypoxia changes membrane potentials and cells become more sensitive to redox insults (Jones, 1985). We hypothesise that this overproduction of free radicals induced by hypoxic conditions could be responsible for the loss of antioxidant activity and for the decrease in antioxidant molecules in the MAP-stored lettuce.

The role played by the single compounds in the antioxidant effect of plant food has not yet been clarified. In the present study, we measured plasma concentrations of quercetin, caffeic acid, $p$-coumaric acid, carotenoids and vitamin $C$, and showed that peak concentrations of these components, except for carotenoids, coincided with the peak in plasma antioxidant capacity. Miller et al. (1998) showed that a diet rich in fruits and vegetables for a period of 8 weeks favourably affected serum antioxidant capacity compared with a control diet low in plant foods, an increase partially explained on the basis of a rise in the concentration of carotenoids. In our present study, the increase in plasma concentration of $\beta$-carotene was not able to modify plasma antioxidant capacity significantly. These results are in agreement with those of Pellegrini et al. (2000), who found that the daily ingestion of $25 \mathrm{~g}$ tomato puree for $14 \mathrm{~d}$ significantly increased lycopene and $\beta$-carotene plasma concentrations in eleven healthy female subjects without significant changes in the antioxidant capacity of plasma. Moreover, Borel et al. (1998) reported a lack of correlation between clinical markers of redox status and concentrations of single carotenoids in healthy subjects. Carotenoids seem not to play a central role in the modulation of plasma antioxidant capacity, although we cannot rule out the possibility that they could be involved in the protective effect of plant food through a different mechanism.

For a long time, the absorption of phenolics from the diet was considered to be negligible and their mechanisms of absorption, distribution, metabolism and excretion were scarcely studied. In recent years, evidence describing the absorption of single phenolic compounds in body fluids after ingestion of onions, red wine, dealcoholised red wine, green tea and chocolate is mounting (Maiani et al. 1997; Serafini et al. 1998; McAnlis et al. 1999; Richelle et al. 1999; Bell et al. 2000). Previous studies (Serafini et al. 1998; McAnlis et al. 1999) showed that the increase in quercetin and total phenolic concentration following an onion meal and dealcoholised red wine ingestion was paralleled by an increase in total antioxidant capacity. In contrast, Caccetta et al. (2000) described how plasma absorption of caffeic acid and 4-O-methylgallic acid was not sufficient to produce an effect on the ex vivo oxidation of serum following red wine ingestion.

Our present results show that the increase of plasma levels of caffeic acid, $p$-coumaric acid and quercetin mirror the increase in plasma antioxidant capacity. However, the in vitro addition of the same phenolic concentrations to a plasma sample (results not shown) does not account for the increase in TRAP shown in vivo. Other factors, other than the plasma concentration of the original compounds present in the food matrix, should play a role in the antioxidant effect of phenolic compounds. The existence of antioxidant metabolites has been reported (Moon et al. 2001) and, although the conjugation with glucuronide and sulfate is a step toward 
detoxification, intermediate products seem to retain their antioxidant activity (Terao, 1999). Moreover, synergistic redox interactions between phenolic compounds and the antioxidant network (Laranjinha \& Cadenas, 1999) could contribute to explaining in part the increase in plasma total antioxidant potential following plant food ingestion. Further research is needed to elucidate the contribution of phenolic compounds to the dietary modulation of antioxidant defences.

\section{Conclusion}

The demonstration that fresh lettuce ingestion is able to raise plasma antioxidant defence sheds further light on the beneficial effect of plant food consumption. The lack of antioxidant effect after consumption of MAP-stored lettuce suggests that until MAP storage conditions are optimised, the consumption of 'fresh' plant food should be encouraged. The development of innovative storage techniques able to preserve the bioactive molecule content of plant food could be a formidable step in promoting the consumption of fresh-cut produce in western countries.

\section{Acknowledgements}

The present study was supported by the Commission of the European Communities, Agriculture and Fisheries (FAIR) specific RTD program, CT 96-1104. The present paper does not necessarily reflect the Commission's views and in no way anticipates future policy in this area. We thank Dr Brian P. F. Day for his helpful advice on the use of MAP technology, Dr Silvia Valtueña Martinez for statistical analyses and the volunteers for their participation and enthusiasm.

\section{References}

Bell JRC, Donovan JL, Wong R, Waterhouse L, German JB \& Walzem RL (2000) (+)-Catechin in human plasma after ingestion of a single serving of reconstituted red wine. American Journal of Clinical Nutrition 71, 103-108.

Block G, Patterson B \& Subar A (1992) Fruit, vegetables and cancer prevention: a review of the epidemiological evidence. Nutrition and Cancer 18, 1-29.

Borel P, Grolier P, Boirie Y, Simonet L, Verdier E, Rochette Y, Gouabau M, Beaufrere B, Lairon D \& Azais-Braesco V (1998) Oxidative stress status and antioxidant status are apparently not related to carotenoid status in healthy subjects. Journal of Laboratory and Clinical Medicine 132, 61-66.

Brecht P (1980) Use of controlled atmospheres to retard deterioration of produce. Food Technology 3, 45-50.

Caccetta RA, Croft KD, Beilin LJ \& Puddey IB (2000) Ingestion of red wine significantly increases plasma phenolic acid concentrations but does not acutely affect ex vivo lipoprotein oxidizability. American Journal of Clinical Nutrition 71, 67-74.

Cao G, Sofic E \& Prior RL (1996) Antioxidant capacity of tea and common vegetables. Journal of Agricultural and Food Chemistry 44, 3426-3431.

Cao G, Booth LS, Sadowski AJ \& Prior RL (1998) Increases in human plasma antioxidant capacity after consumption of controlled diets high in fruit and vegetables. American Journal of Clinical Nutrition 68, 1081-1087.
Ceriello A, Bortolotti N, Motz E, Crescentini A, Lizzio S, Russo A, Tonutti L \& Taboga C (1998) Meal-generated oxidative stress in type 2 diabetic patients. Diabetes Care 21, 1529-1533.

Duthie GG, Duthie SJ \& Kyle AM (2000) Plant polyphenols in cancer and heart disease: implications as nutritional antioxidants. Nutrition Research Reviews 13, 79-106.

Erhola M, Nieminen MM, Kellokumpu-Lehtinen P, Metsa-Ketela T, Poussa T \& Alho H (1997) Plasma peroxyl radical trapping capacity in lung cancer patients: a case-control study. Free Radical Research 26, 439-447.

Gey KF, Brubacher GB \& Stahelin HB (1987) Plasma levels of antioxidant vitamins in relation to ischemic heart disease and cancer. American Journal of Clinical Nutrition 45, 1368-1377.

Ghiselli A, Serafini M, Maiani G, Azzini E \& Ferro-Luzzi A (1995) A fluorescence-based method for measuring total plasma antioxidant capability. Free Radical Biology and Medicine 18, 29-36.

Gil ML, Ferreres F \& Tomas-Barberan FA (1999) Effect of postharvest storage and processing on the antioxidant constituents (flavonoids and vitamin C) of fresh-cut spinach. Journal of Agricultural and Food Chemistry 47, 2213-2217.

Halliwell B (1996) Antioxidants in human health and disease. Annual Review of Nutrition 16, 33-50.

Hertog MGL, Hollman CH \& Venema DP (1992) Optimization of a quantitative HPLC determination of potentially anticarcenogenic flavonoids in vegetables and fruits. Journal of Agricultural and Food Chemistry 40, 1591-1598.

Jones DP (1985) The role of oxygen concentration in oxidative stress: hypoxic and hyperoxic models. In Oxidative Stress, pp. 151-193 [H Sies, editor]. London: Academic Press Inc.

Kader AA, Zagory D \& Kervel EL (1989) Modified atmosphere packaging of fruits and vegetables. Critical Review of Food Sciences and Nutrition 28, 1-30.

Laranjinha J \& Cadenas E (1999) Redox cycles of caffeic acid, $\alpha$-tocopherol, and ascorbate: implications for protection of low-density lipoproteins against oxidation. Life 48, 57-65.

McAnlis GT, McEneny J, Pearce J \& Young IS (1999) Absorption and antioxidant effects of quercetin from onions in man. European Journal of Clinical Nutrition 53, 92-96.

McLemore J, Beeley P, Thorton K, Morrisroe K, Blackwell W \& Dasgupta A (1998) Rapid automated determination of lipid hydroperoxide concentrations and total antioxidant status of serum samples from patients infected with HIV. American Journal of Pathology 109, 268-273.

Maiani G, Pappalardo G, Ferro-Luzzi A, Raguzzini A, Azzini A, Guadalaxara A, Trifero M, Frommel T \& Mobarhan S (1995) Accumulation of beta-carotene in normal colorectal mucosa and colonic neoplastic lesions in humans. Nutrition and Cancer 24, 23-31.

Maiani G, Serafini M, Salucci M, Azzini E \& Ferro-Luzzi A (1997) Application of a new high-performance liquid chromatographic method for measuring selected polyphenols in human plasma. Journal of Chromatography B 692, 311-317.

Margolis SA \& Schapira RM (1997) Liquid chromatography measurement of L-ascorbic acid and D-ascorbic acid in biological samples. Journal of Chromatography B 690, 25-33.

Margolis SM, Robert CP \& Ziegler RG (1990) Ascorbic and dehydroascorbic acids in plasma preserved with dithiothreitol or metaphosphoric acid. Clinical Chemistry 36, 1750-1755.

Miller ER, Lawrence JA \& Risby TH (1998) Effect of dietary patterns on measures of lipid peroxidation. Results from a randomized clinical trial. Circulation 98, 2390-2395.

Moon J, Tsushida T, Nakahara K \& Terao J (2001) Identification of quercetin 3-O- $\beta$-D-glucuronide as an antioxidative metabolite in rat plasma after oral administration of quercetin. Free Radical Biology and Medicine 30, 1274-1285.

Pellegrini N, Riso P \& Porrini M (2000) Tomato consumption 
does not affect the total antioxidant capacity of plasma. Nutrition 16, 268-271.

Powrie WD \& Skura BJ (1991) Modified Atmosphere Packaging of Fruit and Vegetables. Chichester, Sussex: Ellis Horwood.

Richelle M, Tavazzi I, Enslen M \& Offord EA (1999) Plasma kinetics in man of epicatechin from black chocolate. European Journal of Clinical Nutrition 53, 22-26.

Serafini M, Maiani G \& Ferro-Luzzi A (1998) Alcohol-free red wine enhances plasma antioxidant capacity in humans. Journal of Nutrition 128, 1003-1007.

Sharpless KE, Arce-Osuna M, Brown-Thomas J \& Gil LM (1999) Value assignment of retinol, retinyl palmitate, tocopherol and carotenoid concentrations in standard references material 2383 (baby food composite). Journal of AOAC INTERNATIONAL 82, 288-296.
Svendsen CN (1993) Multi-electrode array detectors in high performance liquid chromatography: a new dimension in electrochemical analysis. Analyst 118, 123-129.

Swain T \& Hillis E (1959) The phenolic constituents of Prunus domestica. The quantitative analysis of phenolic constituents. Journal of Science and Food Agriculture 10, $63-68$.

Terao J (1999) Dietary flavonoids as antioxidants in vivo: conjugated metabolites of $(-)$-epicatechin and quercetin participate in antioxidative defense in blood plasma. Journal of Medical Investigation 46, 159-168.

Tsai K, Hsu T, King C, Lin K \& Lu F (2000) Is the endogenous peroxyl-radical scavenging capacity of plasma protective in systemic inflammatory disorders in humans? Free Radical Biology and Medicine 28, 926-933. 